\title{
Competências Requeridas ao Gestor de Unidades de Conservação do Estado do Amazonas
}

\author{
The Profile of the Manager of Conservation Units of the State of Amazonas
}

\section{Competencias Requeridas al Gestor de Unidades de Conservación del Estado de} Amazonas

\author{
Rosana Martiniano Sahdo ${ }^{1}$ \\ rosanamsahdo@yahoo.com.br \\ http://lattes.cnpq.br/8464479409659476 \\ https://orcid.org/0000-0002-5867-3377
}

Gil Vieira ${ }^{1}$ gap@inpa.gov.br http://lattes.cnpq.br/9262271725044155 https://orcid.org/0000-0002-0440-602X

Fabiula Meneguete Vides da Silva ${ }^{2}$ fabiulamv@yahoo.com.br http://lattes.cnpq.br/1562017815638375 https://orcid.org/0000-0001-6073-4506

Jurandir Moura Dutra² jurandirdutra@ufam.edu.br http://lattes.cnpq.br/2235849288384765 https://orcid.org/0000-0002-3198-3818

Instituto Nacional de Pesquisas da Amazônia, INPA, Brasil ${ }^{1}$ Universidade Federal do Amazonas, UFAM, Brasil ${ }^{2}$

Recebido em: 19/03/2021 / Revisão: 19/03/2021 / Aprovado em: 09/11/2021

Editores responsáveis: Prof. Dr. Antônio Giovanni Figliuolo Uchôa e Prof. Dr. Jonas Fernando Petry Processo de Avaliação: Double Blind Review DOI: https://10.47357/ufambr.v3i2.8784 


\title{
Resumo
}

A complexidade das Unidades de Conservação na Amazônia requer gestão por competências para o enfrentamento mais eficaz. Quando o assunto é contratação no setor público, o órgão gestor deve captar no mercado, profissionais qualificados e com perfil adequado para assumir a função. Mas, qual o perfil adequado e como identificá-lo? Neste caso é primordial associar uma gestão estratégica focada em resultados com objetivos e metas bem definidos. Este trabalho apresenta uma abordagem sobre o mapeamento dos conhecimentos, habilidades e atitudes das atividades laborais e sugere o desenho de cargo para auxiliar na seleção do gestor do Sistema de Unidades de Conservação do Estado do Amazonas, Brasil. A pesquisa produziu uma análise descritiva adotando o método do estudo de caso proposto por Yin (2015), empregando como técnicas de coleta de dados entrevistas semiestruturadas e questionários enviados por correio eletrônico, a fim de se obter uma análise quali-quantitativa. $\mathrm{O}$ estudo evidenciou uma equipe composta em sua maioria por jovens gestores, com idade entre 20 a 40 anos, cujo nível de graduação multidisciplinar é da ordem de $47 \%$ e a experiência na função varia de 2 a 10 anos. Os resultados apontam que o gestor precisa ter sólidos conhecimentos sobre administração financeira, planejamento estratégico e operacional e elevado grau de relação interpessoal. Dessa forma, conclui-se que o gestor deve ser um profissional multidisciplinar, com habilidades técnicas e interpessoais capazes de estimular atitudes éticas e compatíveis com o espírito de liderança e negociação em ambiente diverso e submetido a conflitos socioambientais.

Palavras-chave: Gestor Ambiental. Gestão por Competência. Gestão Socioambiental. Perfil do Gestor de Unidades de Conservação.

\section{The Profile of the Manager of Conservation Units of the State of Amazonas}

\begin{abstract}
Conservation units are complex it requires competency management to struggle the challenges more efficiently. When the public sector needs to hire, the managing body should capture in the market qualified professionals with an appropriate profile to assume the position. But, which profile should be appropriated and how to identify them? In this case, it is essential to associate results-oriented strategic management with well-defined objectives and goals. This paper presents an approach on the mapping of knowledge, skills, and attitudes of work activities and suggests the design of position to assist in the selection of the manager of Conservation Units of the Amazonas State System, Brazil. The study performed a descriptive analysis using the case study method proposed by Yin (2015). In this case, data collection techniques are obtained by semi-structured interviews and questionnaires sent by email to obtain a qualitative and quantitative analysis. The study evidenced a team composed mostly of young managers, aged between 20 and 40 years. The academic background is multidisciplinary for $47 \%$ of them and their experience in the position varies from 2 to 10 years. The results indicate that the manager needs to have solid knowledge about financial management, strategic and operational planning and a high degree of interpersonal relationship. Thus, it is concluded that the manager should be a multidisciplinary professional; with technical and interpersonal skills capable of stimulating ethical attitudes compatible with the spirit of leadership and negotiation in a diverse environment and subject to social and environmental conflicts.
\end{abstract}

Keywords: People management. Competence management. Social and environmental management. 
Competências Requeridas ao Gestor de Unidades de Conservação do Estado do Amazonas

\section{Competencias Requeridas al Gestor de Unidades de Conservación del Estado de Amazonas}

\section{Resumen}

La complejidad de las Unidades de Conservación en la Amazonia requiere gestión por competencias para el enfrentamiento más eficaz. Cuando el asunto es contratación en el sector público, el órgano gestor debe captar en el mercado, profesionales cualificados y con perfil adecuado para asumir la función. Mas, ¿cuál es el perfil adecuado y cómo identificarlo? En este caso es primordial asociar una gestión estratégica enfocada en resultados con objetivos y metas bien definidos. Este trabajo presenta un abordaje sobre el mapeo de los conocimientos, habilidades y actitudes de las actividades laborales y sugiere el diseño de cargo para auxiliar en la selección del gestor del Sistema de Unidades de Conservación del Estado de Amazonas, Brasil. La investigación produjo un análisis descriptivo, adoptando el método del estudio de caso propuesto por Yin (2015), empleando como técnicas de recolección de datos entrevistas semiestructuradas y cuestionarios enviados por correo electrónico, a fin de obtener un análisis cualitativo-cuantitativo. El estudio evidenció un equipo compuesto, en su mayoría, por jóvenes gestores, con edades comprendidas entre 20 a 40 años, cuyo nivel de graduación multidisciplinar es del orden de $47 \%$ y la experiencia en la función varia de 2 a 10 años. Los resultados obtenidos aportan que el gestor precisa tener sólidos conocimientos sobre administración financiera, planeamiento estratégico y operacional, además de elevado grado de relación interpersonal. De esa forma, se concluye que el gestor debe ser un profesional multidisciplinar, con habilidades técnicas e interpersonales capaces de estimular actitudes éticas y compatibles con el espíritu de liderazgo y negociación en ambiente diverso y sometido a conflictos socioambientales.

Palabras clave: Gestor ambiental. Gestión por competencia. Gestión socioambiental. perfil del gestor de unidades de conservación. 


\section{INTRODUÇÃO}

O Sistema Nacional de Unidades de Conservação da Natureza (SNUC) instituído pela Lei $\mathrm{n}^{\circ}$ 9.985/2000 define Unidades de Conservação (UC), em seu artigo $2^{\circ}$, § I como sendo o "espaço territorial e seus recursos ambientais, incluindo as águas jurisdicionais, com características naturais relevantes, legalmente instituído pelo Poder Público, com objetivos de conservação e limites definidos, sob regime especial de administração".

Essas Unidades de Conservação depois de criadas carecem de regulamento, cuja gestão deve ser executada pelo Poder Público. O gestor, então, após recrutamento inicia as ações de articulação com os demais atores envolvidos.

$\mathrm{O}$ ato de administrar ou gerir envolve planejamento, ordenamento, comando e controle das atividades. Para garantir eficácia na administração é preciso recrutar e selecionar pessoas qualificadas. Nesse desafio, devem-se implantar modelos e instrumentos de gestão que garantam resultados (Montana \& Charnov, 2003; Tachizawa \& Andrade, 2006).

Entretanto, para o bom desempenho do gestor do complexo mosaico de UC do Estado do Amazonas, em qualquer esfera de governo, é necessária a compreensão de diversos fatores de ordem política e administrativa que interferem no processo de gestão.

Assim, é primordial recrutar e selecionar profissionais capazes de compreender essas barreiras e, ao mesmo tempo, competentes para vencer os desafios inerentes. Mas, qual seria o perfil ideal deste gestor que atenderia às necessidades destes espaços socioambientais que objetivassem atender as competências técnicas e comportamentais?

Uma possível solução passaria pelo mapeamento das competências requeridas pelo sistema e as profissionais identificadas no gestor, a fim de se estabelecerem intersecções matriciais. A gestão por competência é a metodologia mais adequada e utilizada por organizações para identificar perfis profissionais e reconhecer as características pessoais de um indivíduo. Esses atributos podem ser aperfeiçoados ou alinhados às essências institucionais com a tríade Conhecimento, Habilidade e Atitude (CHA) tornando-se referência para atingir o propósito da construção política de gestão de pessoas (Lara \& Silva, 2007).

Por tudo isso, este trabalho teve o objetivo de mapear as competências técnicas e comportamentais necessárias ao desempenho da função do gestor das UC a fim de se elaborar o desenho do cargo suficiente para orientar o processo de recrutamento e seleção, assim como nortear o desenvolvimento de pessoas.

Entende-se que os resultados possam catalisar a reconstrução da cultura institucionalizada e estimular o recrutamento e seleção de gestores contratados para resultados, cuja eficiência possa ser observada e medida como requer o modelo gerencial da nova gestão pública pósburocrática. Sobretudo, espera-se colaborar com a excelência da gestão das Unidades de Conservação no estado do Amazonas.

\section{GESTÃO DAS UCs}

É um grande desafio para o órgão que administra as UCs independemente da esfera administrativa do Estado. As dificuldades de gerir estas unidades no Amazonas surgem 
Competências Requeridas ao Gestor de Unidades de Conservação do Estado do Amazonas

devido a distâncias geográficas, aos acessos e à escassez de recursos financeiros, humanos e tecnológicos.

O papel do gestor é auxiliar diretamente a gestão das UCs com a responsabilidade de apoiar a preservação dos recursos naturais, o desenvolvimento socioambiental e cultural das comunidades tradicionais locais.

Vale ressaltar, que os métodos de avaliação devem prever o comportamento adequado de um candidato ao desempenho da função. Normalmente o selecionador utiliza critérios, etapas e análise do cargo a ser ocupado como estratégia no recrutamento de pessoas. Dessa forma, é possível aferir a experiência, a capacidade técnica e o potencial emocional e intelectual do ser humano (Gil 2001, 2007; Rosa, 2004; Satake, Flogio Junior, Reis, \& Batista, 2011).

Os atos de saber agir, mobilizar recursos, se engajar, assumir responsabilidades e ter visão estratégica podem agregar valor econômico para a instituição e propiciar aspectos sociais para o indivíduo. Os atributos pessoais auxiliam na execução de uma atividade ou cargo, além de propiciar a compreensão e domínio de situações de constantes mudanças. Com isso, esse indivíduo fortalece a equipe de trabalho e passa a ser reconhecido pelos outros (Brandão \& Bahry, 2005; Durand, 1998; Fleury \& Fleury, 2006; Magalhães \& Rocha, 1997; Mello, 2006; Zariffian, 2001).

A reciprocidade entre as competências individuais e as competências organizacionais, possibilita que as pessoas façam uso dos seus patrimônios de competências para enfrentamento em várias situações no dia-a-dia de trabalho. Dessa maneira, as pessoas disponibilizam o seu aprendizado para desenvolver e fortalecer a instituição (Dutra, 2001).

Assim, são necessárias competências para auxiliar na obtenção de resultados e serviços eficientes. Logo, a melhoria do desempenho torna a gestão pública fortalecida (Carvalho et al., 2009). Sem dúvida, pesquisas realizadas por Witt e Almeida (2003), Castro e Campos (2003), Lazzarotto, Cardoso e Nazzari, (2003), Mello (2006), Lima (2010), Zamberlan (2010), Coe (2012) e Araújo Júnior e Martins (2014) nas áreas de educação, saúde e administração mostram que as avaliações das competências favorecem a gestão pública.

\section{EXCELÊNCIA NA GESTÃO DAS UCS}

A gestão de UCs no Brasil de um modo geral é efetuada de forma precária e sem foco em resultados (Araújo, Cabral \& Marques, 2012). Mudanças constantes do sistema desintegram a estrutura organizacional; afetam o sistema de gestão estratégica e de processos (Ministério do Meio Ambiente [MMA] 2007; Drumond, Franco \& Ninis 2006; Lima, 2015).

O processo de gestão envolve a cultura organizacional (valores, visão e ideias), a estrutura organizacional (o formato do organograma) e os mecanismos de gestão (métodos e ferramentas). Nesse sentido, se faz necessário que a instituição se mantenha imparcial em sua estrutura organizacional e invista em recursos humanos e financeiros. Além disso, se deve desenvolver e implantar instrumentos/modelos de gestão e a adoção de políticas públicas que possam auxiliar a gestão (Bergue, 2007; Carvalho et al., 2009; Dutra, 2004; Gramigna, 2007).

O Programa Nacional de Gestão Pública e Desburocratização surgiu em 2005 para melhorar a qualidade dos serviços prestados aos cidadãos e aumentar a competitividade no país. Desde então, com a ideia de avançar a operacionalização na gestão pública, instituiu-se o Modelo de UFAMBR, Manaus, v.3, n.2, art. 5, pp. 77-93, julho-dezembro, 2021http://www.periodicos.ufam.edu.br/ufambr 
Competências Requeridas ao Gestor de Unidades de Conservação do Estado do Amazonas

Excelência como forma de organizar e gerir instituições. Assim, os critérios de excelência são: a) Liderança, b) Estratégias e Planos, c) Clientes e Sociedade, d) Informações e Conhecimento, e) Gestão de Pessoas, f) Gestão de Processos e Resultados. Estes critérios passaram a orientar o desenvolvimento da alta performance organizacional (Ministério do Planejamento, Orçamento e Gestão [MPOG] 2008).

A incorporação de novos instrumentos à gestão de pessoas pode fazer diferença na forma de gerir. As competências técnicas aliadas aos atributos pessoais podem facilitar o papel do gestor de UC como articulador e impulsionador da materialização das ações no campo. Dessa forma, o CHA pode ajudar a eleger pessoas certas para exercer a função gerencial.

Araújo, Cabral e Marques (2012) veem a liderança como o motor da gestão que orienta, motiva e se compromete com os resultados sustentáveis da organização e com o desenvolvimento da cultura da excelência e a defesa dos direitos públicos.

Portanto, a gestão por excelência das UCs deve valorizar os líderes, o trabalho em equipe e renovar a cultura e clima organizacional. Ao operacionalizar a gestão de UCs com foco nos resultados pode-se garantir a implementação da gestão estratégica e da gestão dos processos (MMA, 2007).

\section{PROCEDIMENTOS METODOLÓGICOS}

Este trabalho é uma pesquisa descritiva com procedimento de investigação de estudo de caso e de natureza quali-quantitativa. Ao discorrer sobre as características essenciais dos gestores de UC, a pesquisa estabeleceu as relações entre variáveis que se valem dos métodos de análise quantitativa e qualitativa juntos, como complemento um do outro para obtenção de uma análise mais profunda. No quantitativo, os dados foram avaliados conforme as opiniões dos "atores focos", aplicando técnicas estatísticas descritivas. Já no método qualitativo, os dados receberam tratamento lógico, ou seja, envolvem significados, motivos, aspirações, crenças, valores e atitudes que não podem ser quantificados pelo olhar dos pesquisadores (Boente \& Braga, 2004; Gil, 2007; Gonçalves, 2005).

O universo desse estudo envolveu as 42 Unidades de Conservação do Estado do Amazonas, sendo 8 de Proteção Integral e 34 de Uso Sustentável. Vinte e cinco pessoas que atuam diretamente na gestão dessas unidades fizeram parte do estudo.

Foi escolhido como ferramenta/filosofia o CHA para definir o sentido de competência a partir de um referencial no qual ela pode ser medida e, até mesmo, comparada aos padrões internacionais, por ser considerada uma das metodologias mais atuais e utilizadas pelas empresas para recrutar, desenvolver e avaliar seus profissionais.

Para reconhecer o perfil dos 25 gestores da UC do Estado do Amazonas e enquadrá-los às competências do CHA, foram aplicados questionários com perguntas fechadas e abertas via email, a fim de coletar dados segundo a percepção dos investigados. Antecedendo a aplicação do questionário, realizou-se um pré-teste que possibilitou ajustes com intuito de verificar a clareza, a redundância e a impressão dos investigados. A estrutura do questionário foi adaptada ao modelo aplicado por Lima (2010) em uma pesquisa similar.

A estrutura do questionário conteve três partes distintas, com variáveis quantitativas e qualitativas. A primeira parte refere-se à identificação do perfil dos administradores do 
Competências Requeridas ao Gestor de Unidades de Conservação do Estado do Amazonas

Departamento de Mudanças Climáticas e Gestão de Unidades de Conservação (DEMUC) que é o órgão da estrutrura da Secretaria de Meio Ambiente do Estado do Amazonas (SEMA) com questões subjetivas. A segunda parte (Figura 1) permitiu identificação e o enquadramento do perfil de competências gerenciais, com três indicadores.

\section{Figura 1}

Variáveis/categorias dos indicadores CHA das competências gerenciais do gestor de UC

\begin{tabular}{|c|c|c|}
\hline \multicolumn{3}{|c|}{ VARIÁVEIS /CATEGORIAS } \\
\hline Indicador Conhecimento & Indicadores Habilidades & Indicador Atitudes \\
\hline $\begin{array}{ll}\text { 1. } & \text { Politica Institucional } \\
\text { 2. } & \text { Administração/Finanças } \\
\text { 3. } & \text { Planejamento Estratégico Operacional } \\
\text { 4. } & \text { Gestão de pessoas } \\
\text { 5. } & \text { Processo de tomada de Decisão } \\
\text { 6. } & \text { Conhecimento em Informática } \\
\text { 7. } & \text { Psicologia Organizacional }\end{array}$ & $\begin{array}{ll}\text { 1. } & \text { Planejamento } \\
\text { 2. } & \text { Organização } \\
\text { 3. } & \text { Liderança } \\
\text { 4. } & \text { Decisão } \\
\text { 5. } & \text { Comunicação/Saber ouvir } \\
\text { 6. } & \text { Análise e Sintese } \\
\text { 7. } & \text { Trabalho em Equipe } \\
\text { 8. } & \text { Criatividade/Inovação } \\
\text { 9. } & \text { Execução } \\
\text { 10. Inspiração e Motivação da Equipe } \\
\text { 11. Administração de conflito e negociação } \\
\text { 12. Relações Interpessoais } \\
\text { 13. } & \text { Articulação de Recursos }\end{array}$ & $\begin{array}{ll}\text { 1. } & \text { Etico } \\
\text { 2. } & \text { Autoconfiança } \\
\text { 3. } & \text { Determinado } \\
\text { 4. } & \text { Flexivel } \\
\text { 5. } & \text { Responsável } \\
\text { 6. } & \text { Servidor/Cuidadoso } \\
\text { 7. } & \text { Comprometido } \\
\text { 8. } & \text { Auto motivado } \\
\text { 9. } & \text { Visionário } \\
\text { 10. } & \text { Aprendiz/Educador }\end{array}$ \\
\hline
\end{tabular}

Fonte: Adaptado de Lima (2010)

A terceira parte relaciona perguntas que refletem desenvolvimento profissional com questões abertas. Na intenção de reforçar e aprofundar o questionário foram realizadas entrevistas presenciais com oito gestores.

Dessa forma, as entrevistas semiestruturadas foram norteadas buscando compreender os aspectos comportamentais associados às qualidades individuais eleitas por Sabbag (2007).

Este estudo foi submetido e aprovado pelo Conselho de Ética do Instituto Nacional de Pesquisas da Amazônia - INPA e está registrado no Conselho Nacional de Ética da Pesquisa (CONEP) e disponível em CAAE: 70191417.1.0000.0006.

Os dados foram organizados e tabulados para a construção de gráficos e análise estatística descritiva. A frequência das variáveis, foram escolhidas e classificadas pelos gestores e, em seguida, realizou-se o cruzamento dos dados para verificar a tendência nas categorias. Por último, as falas transmitidas pelos gestores foram descritas e inferidas.

O DEMUC administra 42 UC distribuidas nas categorias definidas no Sistema Estadual de Unidade de Conservação, sendo oito de Proteção Integral e trinta e quatro de Uso Sustentável.

\section{RESULTADOS}

\subsection{Identificações do gestor de UC}

Após a realização das entrevistas e análises dos questionários pode-se obter as identificações. Dos 25 questionários enviados aos gestores das UC estadual, apenas 17 (68\%) foram 
respondidos. Nesse universo trabalhado: $76,5 \%$ são do sexo masculino e $23,5 \%$ do sexo feminino.

Dos respondentes, 15 (quinze) eram gestores efetivos $(88,2 \%$ ), enquanto 2 (dois) eram monitores ambientais $(11,8 \%)$. Esses profissionais estão distribuídos nas categorias de Proteção Integral (17,6\%) e de Uso Sustentável (82,4\%). A maioria (64,7\%) administra unidades de categoria de Uso Sustentável classificada como Reserva de Desenvolvimento Sustentável (RDS).

Grande parte dos gestores do Amazonas tem alguns anos de experiência trabalhando em UC. Acima de 10 anos (5,9\%), de 8 a 10 anos (41,2\%), de 5 a 7 anos $(29,4 \%)$, de 2 a 4 anos $(17,6 \%)$ e menos com 2 anos $(5,9 \%)$. Atuando na função e no cargo de gestor no campo destacou-se: entre 6 a 10 anos $(58,8 \%)$, de 2 a 5 anos (35,3\%) e menos de 2 anos $(5,9 \%)$, cuja jornada de trabalho geralmente é de 40 horas semanais. Contudo, conforme ressaltou o Gestor 1 a carga e o comprometimento são bem mais expansivos, pois "não há carga horária específica. Somos gestores 24 horas".

Confirmou-se, ainda, que boa parte dos administradores dispõe de competência técnica adquirida no ambiente de educação formal. Aproximadamente $29,4 \%$ são pós-graduados com título de especialista e/ou mestre, $47,1 \%$ são graduados e $23,5 \%$ são técnicos ou possuem somente o nível médio.

A função de gestor no organograma da SEMA equivale à do gerente comissionado. Do quadro atual constata-se que aproximadamente $71 \%$ passaram por processo seletivo para exercê-la enquanto 29\% recebeu alguma indicação/nomeação técnica e/ou política. Mesmo frente às incertezas geradas pela rotatividade de pessoal dos órgãos públicos cerca de $94 \%$ dos servidores desejam manter-se na função.

O provimento mensal de um profissional que atua na estrutura do DEMUC varia de acordo com a forma de contratação. Os monitores ambientais $(11,8 \%)$, contratados pela Agência Amazonense de Desenvolvimento Econômico e Social (AADES), recebiam um salário mensal de $\mathrm{R} \$ 3.500,00$ (três mil e quinhentos reais) em regime da Consolidação das Leis do Trabalho (CLT). Já os gestores contratados pela SEMA recebiam entre R \$ 3.500,00 (três mil e quinhentos reais) a $\mathrm{R} \$ 4.500,00$ (quatro mil e quinhentos reais), cujas contratações ocorreram entre os anos de 2008 e 2012.

Do universo de UC estudadas, percebe-se que 15 (quinze) $(88,2 \%$ ) recebe recursos financeiros para implementar o processo de gestão, enquanto 2 (duas), $(11,8 \%)$ não recebe. A maioria das UC é apoiada pelo Programa de Áreas Protegidas da Amazônia (ARPA), do governo federal. O Fundo Brasileiro para Biodiversidade também é uma importante fonte de recursos oriundos do setor privado, órgãos públicos federais, estaduais e da sociedade civil.

\subsection{Identificações do perfil da competência gerencial}

Os resultados obtidos neste estudo possibilitaram sugerir o perfil adequado para o servidor que pretende exercer a função de gestor de UC no Estado do Amazonas. Vale ressaltar que as sugestões foram mais compatíveis com as competências comportamentais. Para o Gestor 2 "[...] é preciso avaliar o desempenho dos gestores nas ações que lhe competem". O Gestor 3 diz que "[...] o gestor necessita ser capacitado, ter autonomia na gestão da UC e saber ouvir as críticas". Já o Gestor 5 afirma que "[...] a primeira coisa é gostar do que faz. Estudar leis, se 
especializar em informática, se articular com o poder público, se aproximar das lideranças locais para distribuir tarefas e envolver a sociedade civil no processo de construção de conhecimento local".

As variáveis/categorias que foram mais assinaladas nos indicadores dos conhecimentos pelos gestores como sendo de extrema importância, atribuídas ao "perfil adequado" desse profissional na gestão das UC, foram: gestão de pessoas com 45\% seguindo de administração/finanças e planejamento estratégico operacional da ordem de 43\% (Figura 2).

\section{Figura 2}

Grau de importância do indicador cognitivo Conhecimento

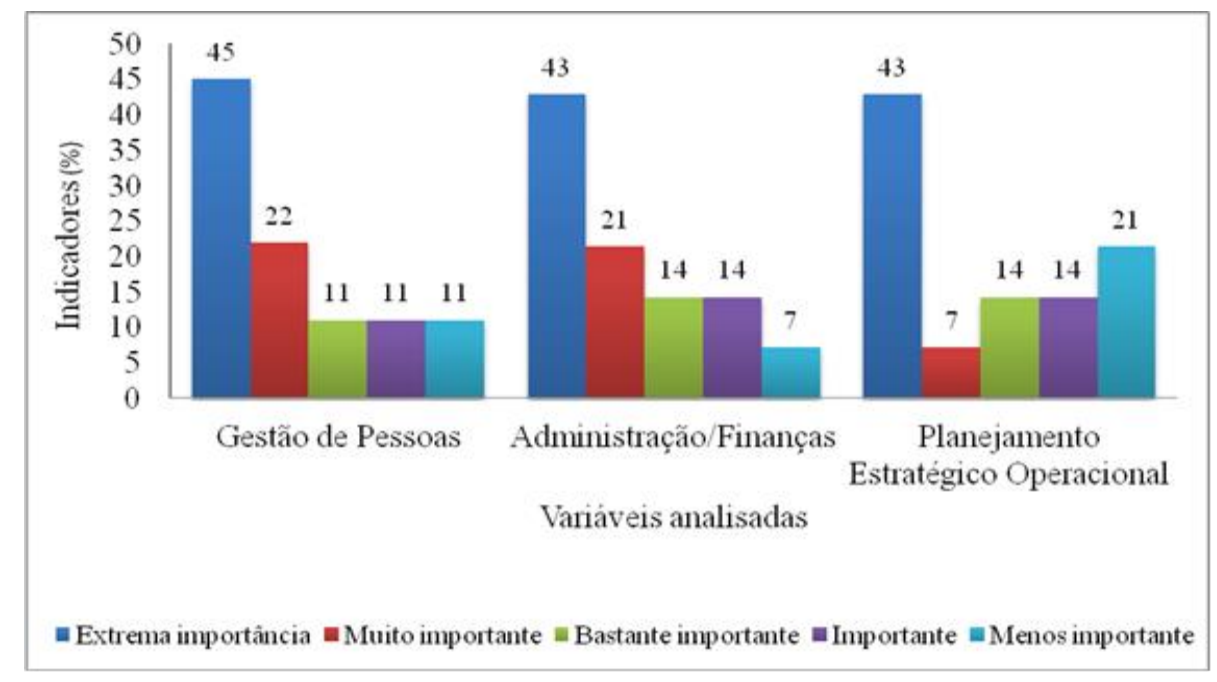

Fonte: Dados da Pesquisa, 2017.

As variáveis do indicador comportamental de habilidades, o qual se refere ao Saber fazer, expressam a capacidade de aplicar os conhecimentos teóricos no dia a dia do trabalho. $\mathrm{O}$ Figura 3 mostra que a variável liderança foi considerada de extrema importância para os gestores (somadas as respostas consideradas de extrema importância, muito e bastante importantes), pois representou $80 \%$ das indicações, assim como o planejamento (86\%) deverá favorecer cumprimento das metas beneficiando o trabalho em equipe (67\%). Trabalho em equipe foi a variável que obteve um resultado interessante, pois as respostas de Extrema Importância e Menor Importância (em extremos opostos da escala) apresentaram a mesma proporcionalidade $(23 \%)$, porém, o que mais se destacou foi o retorno obtido na resposta de Bastante Importante com $31 \%$. 


\section{Figura 3}

Grau de importância do indicador comportamental Habilidade

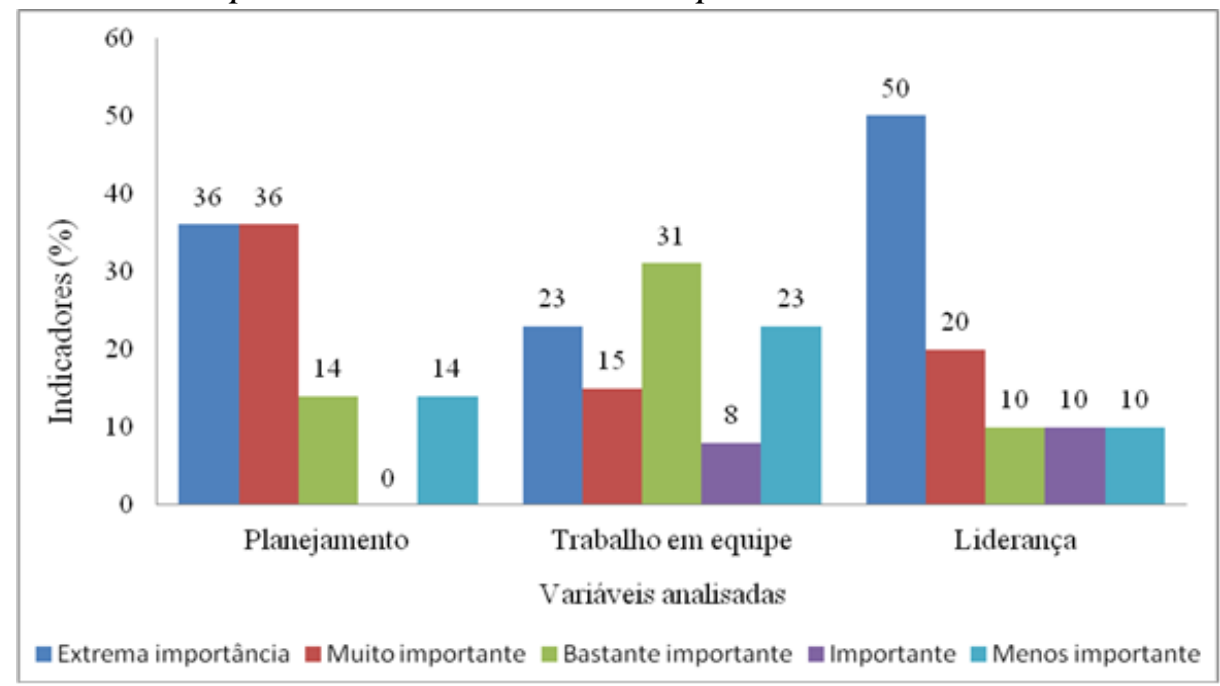

Fonte: Dados da Pesquisa, 2017.

Os resultados revelaram as variáveis que mais se destacaram na percepção dos administradores do DEMUC, sobretudo, aos indicadores comportamentais vinculados a atitudes, ou seja, Querer Ser/Fazer, a partir da decisão e motivação pessoal. Ética foi a variável que apresentou significativa relevância, pois $57 \%$ sinalizaram sê-la de extrema importância. Quando considerada a flexibilidade observa-se pouca relevância atribuída a ela, pois $36 \%$ consideraram-na menos importante. Entretanto, dentro as variáveis analisadas, o comprometimento foi o mais expressivo, uma vez que somadas as respostas das três primeiras escalas de gradação (Extrema Importância, Muito Importante e Bastante Importante) obtevese $92 \%$ de concordância (Figura 4).

\section{Figura 4}

Grau de importância do indicador comportamental Atitude

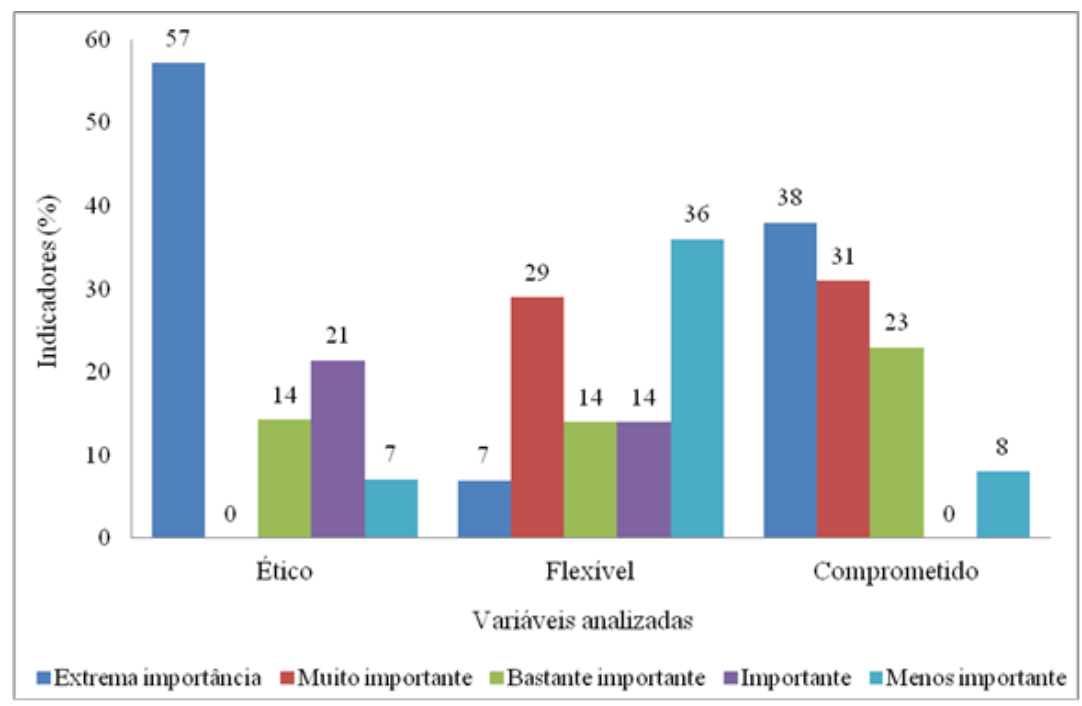

Fonte: Dados da Pesquisa, 2017. 
Durante as entrevistas o Gestor 6 destacou as aptidões que o levou a ter sucesso na gestão da UC, afirmando assim: "tenho que ser otimista, pé no chão, ter visão sistêmica, ser honesto e político". O Gestor 5 separou as competências em quatro âmbitos: 1) âmbito emocional: compatível à inteligência emocional no trabalho; 2) âmbito gerencial: ser organizado e saber se relacionar bem; 3) âmbito de conhecimentos técnicos gerais: ter conhecimento do pacote Office (Word, Excel, PowerPoint), internet e noções básicas de geoprocessamento; 4) âmbito prático: capacidade de identificar defeitos nos equipamentos (carros, motos, voadeiras e drones); destreza no uso de equipamentos de georreferenciamento, assim habilitação para primeiros socorros e sobrevivência na selva, mas, também, aptidão para conduzir reunião.

As características mapeadas sobre a competência denominada CHA (Figura 5) revelou as variáveis mais importantes, identificadas nos indicadores cognitivo e comportamental, como sendo as requeridas ao gestor de UC.

\section{Figura 5}

Características de Conhecimentos (C), Habilidades (H) e Atitudes (A) esperadas do gestor de UC

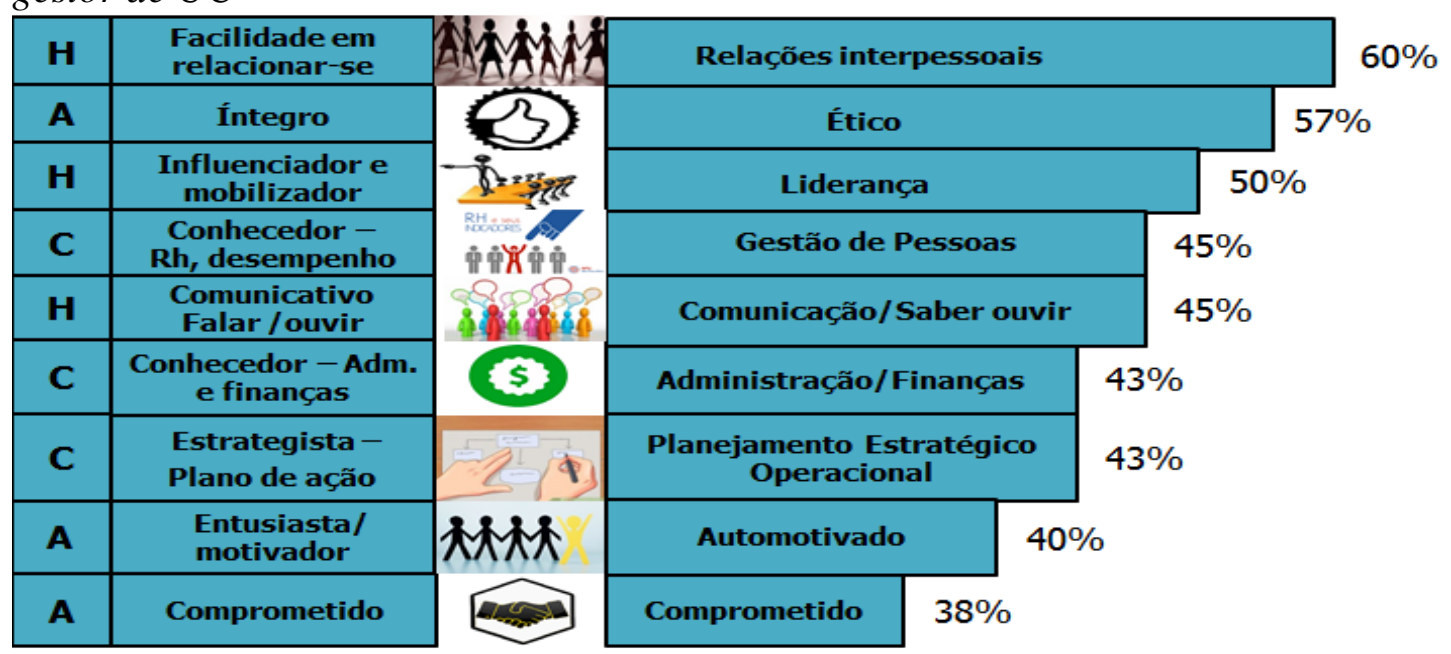

Fonte: Dados da Pesquisa, 2017.

Percebe-se que as habilidades de relacionamento interpessoal (60\%) e as atitudes éticas foram as mais sinalizadas (57\%). Essas características mapeadas auxiliaram na construção do desenho ou descrição do cargo do gestor de UC como sendo o perfil requerido ao exercício da função (Figura 6). 
Competências Requeridas ao Gestor de Unidades de Conservação do Estado do Amazonas

\section{Figura 6}

Desenho de cargo do gestor de UC integrante do quadro do DEMUC

CARGO: Gerente de UC

ÁREA: Ambiental

MISSÃO: Administrar as UCs conforme seus objetivos e as metas do planejamento estratégico institucional.

ATIVIDADES: Conhecer sobre administração em recursos humanos e finanças (custos, captação de recursos e legislação), ter capacidade de construir planos de ação (diagnóstioo, definição de prioridades, monitoramento/avaliação), capacidade de planejar, definir e compartilhar metas estratégicas e táticas, experiência em elaborar projetos, bom relacionamento interpessoal (comunicação, administração de conflito, negociação e formação de equipe), habilidade de influenciar e mobilizar pessoas (envolvidas direta e indiretamente no trabalho), facilidade comunicação (falar e saber ouvir), experiência em trabalhar em equipe, habilidade de articulação (moradores, usuários, prefeitos e políticos e parceiros), presidi o conselho consultivo, capacidade de cuidar da proteção e monitoramento Ambiental, saber conduzir a recepção de visitantes, fazer palestras, organizar eventos e saber utilizar bússola e GPS.

OBS: Ponto para cada item (1): a) dirigir veículos; b) pilotar voadeira c) pequenas lanchas.

FORMAÇÃO:

Mínima: Ensino médio completo

Pontuaçãoo nível: Técnico (1) Graduação (2) Especialização (3) Mestrado (4) Doutorado (5)

ÁREAS DE FORMAÇÃo: Exatas/Humanas/Biológicas/Sociais/Educação

EXPERIÊNCIA:(pontuação com comprovação)

Atuação na gestão de UC Amazônia: Cargo de chefia ou cargo administrativo em instituições públicas, privadas ou mista (1);

Trabalhos na Amazônia em instituições públicas, privadas ou mista (1);

Trabalhos junto as associações comunitárias e populações tradicionais da Amazônia (1).

Fonte: Dados da Pesquisa, 2017.

Assim, o gestor de UC do Estado do Amazonas precisa ter formação multidisciplinar agregada a conhecimentos técnicos e culturais construídos em ambiente de conflitos, cujo comportamento seja compatível com a adoção de posturas éticas, comprometidas e suficientes para apresentar resultados de gestão integrada e participativa.

\section{Discussão}

Um estudo realizado em 45 UC do Estado de Minas Gerais apresentou um quadro onde $68,9 \%$ são gestores do sexo masculino e $31,1 \%$ do sexo feminino, com idade média de 38,6 anos (Alves, Rezende, Borges, Fontes, \& Alves, 2011). Este resultado é coerente com a estratificação de gênero observada no Estado do Amazonas, cuja proporcionalidade entre os sexos é desigual, sendo que o masculino chega a representar quase $3 / 4$ do quadro, em ambas as situações.

Talvez, alguns fatores observados nesta pesquisa podem estar atuando para dificultar a gestão das UC, tais como as dimensões territoriais e suas respectivas áreas de influência, o restringido quadro de pessoal e a escassez dos recursos financeiros. A carência de pessoal e a má distribuição de servidores são um dos maiores problemas para administrar UC no Brasil. Pesquisas realizadas em UC nos Estados de Minas Gerais e Rio de Janeiro confirmam a carência de recursos humanos, principalmente em unidade da categoria de Proteção Integral (Lima, Ribeiro, \& Gonçalves, 2005; Primo \& Pellens, 2000). Os gestores das UC estaduais $(52 \%)$ desejam ter uma equipe formada com pelo menos três a cinco pessoas. "A maior dificuldade que eu enfrento na gestão da UC é a falta de recursos humanos [...] não tenho expectativa para o futuro, não tem quadro efetivo" (Gestor 7).

Outro grande problema observado é a rotatividade de pessoal, cuja motivação está relacionada a questões políticas. Entretanto, 15 dos gestores contratados pela (SEMA), permaneceram no cargo e na gestão das UC mesmo com as mudanças atuais de governos. Contudo, estes profissionais expressaram a necessidade da realização de um concurso público para respectiva efetivação, vez que sentem fragilidade no vínculo empregatício (Pesquisa de campo, 2017). 
Competências Requeridas ao Gestor de Unidades de Conservação do Estado do Amazonas

A extrapolação da carga horária semanal de 40 horas é um fator preocupante e que pode adoecer o gestor. Provavelmente, seja necessário capacitá-lo para gerenciar melhor o tempo durante a realização de suas atividades, de modo a adquirir habilidade para o planejamento satisfatório das tarefas e ações necessárias ao desempenho da função. Para Maitland (2000), o planejamento pode trazer vários benefícios como maior controle, aumento da produtividade $\mathrm{e}$ do tempo livre, mas também, maior transparência.

Contudo, as ações e atividades uma vez planejadas, podem ser interrompidas antes de sua execução. Ao avaliar as UC geridas pelo Estado após mudança de governo, Lima (2015) comprovou que, após a extinção do Centro Estadual de Unidades de Conservação (CEUC), a alteração no organograma institucional ocasionou desintegração da equipe de trabalho, acarretando o não cumprimento de metas e resultados, por não existir uma política pública de Estado neste sentido ou um pacto administrativo.

De toda forma, o salário desses profissionais parece estar defasado no mercado, uma vez que o Guia de Profissões e Salários [CATCHO] (2017) aponta que a média salarial de um gerente operacional no Brasil (associação por equivalência arbitrária) gira em torno de R \$ 5.541,32. A função de gestor de UC exige bastante empenho, então a remuneração e os riscos à integridade física, devido à exposição aos conflitos socioambientais entre os atores e fenômenos naturais, pode reduzir a atratividade na seleção destes profissionais. Esse fato tem sido observado em vários estudos que avaliam a remuneração e as condições de trabalho como motor de atratividade profissional (Alves, Rezende, Borges, Fontes, \& Alves, 2011; Drummond, Franco, \& Ninis, 2006).

A competência técnica do gestor foi observada, vez que a maioria absoluta dos contratados são graduados ou especialistas/mestres. Todavia o conhecimento não é somente adquirido na estrutura formal de ensino ou medido por grau de escolaridade, mas construido no ambiente organizacional e no contexto socioambiental em que o profissional está inserido. Bitencourt (2001) afirma que a avaliação por competência ou desempenho está relacionada às práticas de aprendizagem organizacional e precisam ser amadurecidas e sistematizadas para garantir resultados. Assim sendo, a inserção das competências do CHA no processo de seleção pode facilitar o árduo desafio das instituições gestoras de áreas protegidas no Brasil em encontrar os melhores profissionais do mercado. O reconhecimento do perfil desejado do candidato à função de gestor de UC pode proporcionar às instituições administradoras trabalhar com metas, melhorar as práticas e aumentar a produtividade.

O gestor de UC do Estado do Amazonas também demonstrou a habilidade de captar recursos financeiros. No desenvolvimento de suas atividades laborais, os gestores mais experientes usam algumas estratégias. Este fato é ilustrado nas falas de três deles. O Gestor 2 diz: “[...] participo de editais". Já o Gestor 3 declara que: “[...] procuro parcerias com instituições externas e apoio das instituições que compõem o Conselho". Enquanto, o Gestor 4 afirma que: "[...] estou sempre fazendo articulação em redes sociais viabilizando apoio de parceiros, elaboro projetos e às vezes consigo obter recurso financeiro dos Termos de Ajustamento de Conduta Ambiental" (Pesquisa de campo, 2017).

Entretanto, 41,2\% dos entrevistados apoiam ou participam de algum trabalho social ou voluntário fora das UC. Os gestores mais experientes auxiliam os movimentos sociais; elaboram projeto para organizações da sociedade civil, apoiam atividades em outras UC, colaboram nas atividades dos agentes ambientais voluntários e promovem cursos práticos de compostagem de lixo orgânico e hortas 
caseiras às pessoas no município onde a UC está inserida. A capacidade de envolvimento em atividades paralelas à gestão da UC com cunho socioambiental pode estar associada às habilidades comportamentais requeridas à gestão de equipes. É possível observar que as competências comportamentais são mais significativas que as técnicas, talvez em face da multidisciplinaridade que a função exige.

Está cada vez fica mais evidente que atuar em UC, diante de situações complexas ou de risco de uma atividade a ser realizada, exige que o profissional se sobressaia em situações inéditas, surpreendentes e desafiadoras no trabalho ou nas atividades em ambiente imprevisível e dinâmico. Profissionais que tomam a iniciativa e são proativos tem a capacidade de fazer a diferença na ocupação de seus cargos (Santos, 1999).

Cada Unidade de Conservação é um universo distinto e quanto maior a pressão externa mais difícil fica a gestão da mesma. Quanto maior a proximidade desta UC a um grande centro urbano, maior será a pressão sobre ela. Assim, maiores serão os desafios e consequentemente, maior a necessidade de se adquirir competências e ter uma equipe adequada, dinâmica e participativa.

\section{Considerações Finais}

Este trabalho buscou identificar o perfil do profissional que atenda às necessidades da gestão de UC no Estado do Amazonas e definir as competências necessárias para compor o desenho ou descrição do cargo, com intuito de auxiliar os futuros processos de recrutamento e seleção, mas também orientar a construção de programas de treinamento/capacitação, em processo de retroalimentação dos subsistemas de recursos humanos.

No mapeamento foram descritos os conhecimentos, habilidades e atitudes que devem ser inerentes à função do gestor.

As competências (gestão de pessoas, administração financeira e planejamento estratégico operacional), bem como as habilidades (relações interpessoais, liderança e comunicação) e as atitudes (ética, automotivação e comprometimento) foram as mais destacadas como necessárias ao exercício da função.

O conjunto dessas competências compõe o perfil do profissional. As informações obtidas nesta investigação podem subsidiar as futuras contratações e capacitar, além de desenvolver a equipe. A escolha de profissionais eficientes e eficazes ajustados às competências organizacionais e socioambientais deve auxiliar o processo de gestão e promover a consecução de metas.

Sugere-se, no entanto, pesquisas voltadas a desenvolver e avaliar modelos que auxiliam na tomada de decisão em consonância com as competências aqui definidas, a fim de se promover melhorias na gestão destas UC.

Por fim, espera-se com esse estudo estimular o processo de (re)construção da cultura organizacional do órgão gestor, permitindo inovação no setor público, com práticas alinhadas a modelos gerenciais de gestão pública, buscando resultados produtivos e eficientes, aos moldes da nova gestão pública pós-burocrática. 


\section{REFERÊNCIAS}

Agência Amazonense de Desenvolvimento Econômico e Social. (2015). Processo Seletivo Simplificado (PSS) para contratação de 14 profissionais para atuar como monitor ambiental no projeto: Gasoduto Coari-Manaus, que será executado em parceria com a Secretaria de Estado de Meio Ambiente - SEMA. (Edital No019/2015 - Projeto Gasoduto Coari - Manaus). Recuperado em 22 de março de 2017 de www.aades.am.gov.br/.../aades-abre-inscricoes-para-processo-seletivosimplificado-ga.

Alves, R. G., Rezende, J. L. P., Borges, L. A. C., Fontes, M. A. L., \& Alves, L. W. R. (2011). Perfil e percepção dos chefes de unidade de conservação do sistema estadual de áreas protegidas em Minas Gerais. Soc. Nat. (Online) Vol. 23, n.2, Uberlândia. Disponível em: 〈http://dx.doi.org/10.1590/S1982-45132011000200016〉. Acesso: 10 set. 2017.

Araújo Júnior, J. A., \& Martins, I. (2014). Gestão Por Competências na Administração Pública: Uma Análise Bibliométrica a partir do Decreto Lei 5.707/2006. Revista Gestão. Org. - Revista Eletrônica de Gestão Organizacional, Vol. 12, n. 2 pp. 153162. ISSN 1679-1827. Recuperado em 29 de abril de 2017 de http://www.revista.ufpe.br/gestaoorg>.

Araújo, M. A. R., Cabral, R. F. B., \& Marques, C. P. (2012). A gestão de Resultado para Unidades de Conservação. NEXUCS (Org.) Unidade de Conservação no Brasil: o caminho da gestão para resultados. São Carlos: Ed. RIMA p. 213-238.

Bergue, S. T. Gestão de Pessoas em Organizações Públicas. (2007). 2 ${ }^{\mathrm{a}}$ ed. rev. e atual. Caxias do Sul: Educs.

Bitencourt, C. C. (2001). A gestão de competências gerenciais: A contribuição da aprendizagem organizacional. Tese (Doutorado) - Universidade Federal do Rio grande do Sul. Escola de administração. Programa de Pós Graduação em Administração, Porto Alegre.

Boente, A., \& Braga, G. (2004). Metodologia Científica Contemporânea: para Universitários e Pesquisadores. Rio de Janeiro: Editora Brasport.

Brandão, H. P., \& Bahry, C. P. (2005). Gestão por competências: métodos e técnicas para mapeamento de competência. Revista do Serviço Público, Brasília, Vol. 56, n.2, 2005. pp.179-194.

Castro, E. A. B., \& Campos, E. M. S. (2003). Uma Discussão sobre as Competências e Habilidades de Gestores no Âmbito do Sistema Público de Saúde. Revista APS, Vol.6, n.2, 2003. pp.94-98.

Carvalho, A. I., Vieira, A. S., Bruno, F., Motta, J. I. J., Baroni, M., Macdowell, M. C., Salgado, R., \& Côrtes, S. C. (2009). Escola de Governo e Gestão por Competências: Mesa Redonda de Pesquisa e Ação. Brasília: ENAP

Coe, R. 2012. The nature of educational research - exploring the different understandings of educational research. In: Arthur, J.; Waring, M.; Hedges, L. V. (Eds). Research Methods and Methodologies in Education. London: SAGE. p. 5-20.

Durand, T. (1998). Forms of incompetence. In: International Conference on CompetenceBased Management. Proceedings of the fourth international conference on competence-based management. Oslo: Norwegian School of Management.

Dutra, J. S. (2001). Gestão por competências. São Paulo: Gente.

Dutra, J. S. (2004). Competências: conceitos e instrumentos para a gestão de pessoas na empresa moderna. São Paulo: Atlas. 
Competências Requeridas ao Gestor de Unidades de Conservação do Estado do Amazonas

Drummond, J. A., Franco, L. A., \& Ninis, A. B. (2006). O estado das áreas protegidas do Brasil - 2005. Brasília: MMA.

Fleury, A., \& Fleury, M. T. L. (2006). Estratégias Empresariais e Formação de Competências. 3. ed. São Paulo: Atlas.

Gil, A. C. (2001). Gestão de Pessoas: enfoque nos papéis profissionais. São Paulo: Atlas.

Gil, A. C. (2007). Métodos e Técnicas de Pesquisa Social. 6. ed. São Paulo: Atlas.

Gonçalves, H. de A. (2005). Manual de Metodologia da Pesquisa Científica. São Paulo: Avercamp.

Gramigna, M. R. (2007). Modelo de Competências e Gestão dos Talentos. 2. ed. São Paulo: Prentice Hall.

Guia de profissões e salários. ((2017). Recuperado em 01 de dezembro de 2017 de http://www.guiadacarreira.com.br/salarios/quanto-ganha-um-administrador/>.

Lara, J. F.; \& Silva, M. B. (2007). Avaliação de desempenho no modelo de gestão por competências: uma experiência de utilização. Trabalho de Conclusão De Curso (Graduação em Psicologia) - Universidade Tuiuti do Paraná. Recuperado em 08 de abril de 2017 de https://pt.scribd.com/.../Avaliacao-de-Desempenho-No-Modelo-deGestao-Por-Compe.

Lazzarotto, E. M.; Cardoso, G. M.; \& Nazzari, R. K. (2003). Conhecimento, habilidade e atitude requeridas para o enfermeiro gerenciar as unidades básicas de saúde. In: Anais Seminário Nacional Estado Políticas Sociais no Brasil, Cascavel. Programa e Resumo do Seminário Nacional Estado e Políticas Sociais no Brasil. Cascavel: Edunioeste, v. 1. p. 62-63, 2003.

Lei $n^{\circ}$ 9.985, de 18 de julho de 2000. (2000). Institui o Sistema Nacional de Unidades de Conservação da Natureza: Diário Oficial da União de 19/07/2000.

Lima, A. K. C. (2010). Competências gerenciais: a percepção dos gestores da IES pública. 134 (59-66). Dissertação (Mestrado em Administração) - Universidade Potiguar. Natal. Recuperado em 27 de dezembro de 2016 de https://unp.br/wpcontent/uploads/2013/12/Andrea-Kaliany-da-Costa-Lima-Compet\%C3\%AAnciasGerenciais-a-Percep\%C3\%A7\%C3\%A3o-dos-Gestores-de-uma-IESP\%C3\%BAblica1.pdf.

Lima, G. S., Ribeiro, G. A., \& Gonçalves, W. (2005). Avaliação da Efetividade de Manejo das Unidades de Conservação de Proteção Integral em Minas Gerais. Revista Árvore, Viçosa, vol. 29, n. 4, pp. 647-653.

Lima, R. (2015). Organizações avaliam o Sistema Estadual de Unidades de Conservação do Amazonas. Recuperado em 24 de abril de 2017 de http://www.idesam.org.br/organizacoes-avaliam-o-sistema-estadual-de-unidades-deconservacao-do-am/.

Maitland, I. (2000). Administre seu tempo. São Paulo: Nobel.

Magalhães, S; \& Rocha, M. (1997). Desenvolvimento de competências: o futuro agora! Revista de São Paulo, Treinamento e Desenvolvimento pp.12-14.

Mello, M. S. N. (2006). Competências e habilidades requeridas para o exercício de função gerencial em Instituições Federais de Ensino. In. Cadernos Temáticos, n.12 pp.5359.

Ministério de Meio Ambiente. (2007). Secretaria de Biodiversidade e Florestas. Diretoria do Programa Nacional de Áreas Protegidas da Amazônia. ARPA-Áreas protegidas da Amazônia. Brasília: MMA.

Ministério do Planejamento, Orçamento e Gestão. (2008). Secretaria de Gestão. Programa Nacional de Gestão Pública e Desburocratização - GESPÚBLICA; Prêmio Nacional da Gestão Pública - PQGF; Instrumento para Avaliação da Gestão Pública - ciclo 2008/2009. Versão 1/2008. Brasília: MP, SEGES. 
Montana, P. J., \& Charnov, B. H. (2003). Administração. Tradução de Robert Brian Taylor. São Paulo: Saraiva.

Primo, P. B. S., \& Pellens, R. (2000). A situação atual das Unidades do Estado do Rio de Janeiro. In: Congresso Brasileiro de Unidades de Conservação, 2, 2000, Campo Grande. Trabalhos Técnicos, Campo Grande (Vol.2, pp. 628-637).

Rosa, E. S. (2004). Recrutamento e seleção de pessoal: quais as vantagens deste processo para uma organização? São Paulo: Faculdade Oswaldo Cruz. Recuperado em 20 de fevereiro de 2016 de http://www.oswaldocruz.br/download/artigos/social22.pdf >.

Sabbag, P. Y. (2007). Espirais do conhecimento: ativando indivíduos, grupos e organizações. São Paulo: Saraiva.

Santos, F. C. A. (1999). Estratégia de recursos humanos: dimensões competitivas. São Paulo: Atlas.

Satake, E. F., Fóglio Júnior, E., Reis, F., \& Batista, R. M. (2011). Recrutamento e Seleção com Foco no Recrutamento Interno. Universitária - Revista Científica do Unisalesiano, Lins, São Paulo, ano 02, n. 4, jul./dez.

Tachizawa, T., \& Andrade, R. O. B. (2006). Gestão de instituições de ensino. (4 ed.), rev. e ampl. Rio de Janeiro: FGV.

Witt, R. R., \& Almeida, M. C. P. (2003). Competências dos Profissionais de Saúde no Referencial das Funções Essenciais de Saúde Pública: contribuição para a construção de Projetos Pedagógicos na Enfermagem. Rev. BrasEnferm, Brasília (DF) 56(4), pp.433-438.

Yin, R.K. (2015). Estudo de Caso: planejamento e métodos/ Robert K. Yin; trad. Daniel Grassi. - 3. ed. - Porto Alegre: Bookman.

Zamberlan, C. O., \& Cerreta, P. S. (2010). Orientação para competências na gestão das instituições de ensino superior públicas e privadas: o caso da região de Santa Maria -RS. Qualit@s Revista Eletrônica. ISSN 1677 4280. Vol.9, nº 2.

Zariffian, P. (2001). Objetivo competência: por uma nova lógica. Tradução de Maria Helena C. V. Trylinski. São Paulo: Editora Atlas S.A. 